\title{
UM OLHAR SOBRE OS RESULTADOS BRASILEIROS NO PISA 2015: POSSIBILIDADES DE SE REFLETIR SOBRE PROBLEMAS DO ENSINO DE CIÊNCIAS E À FORMAÇÃO INICIAL DO PROFESSOR DE CIÊNCIAS
}

\section{MARCOS GERVÂNIO DE AZEVEDO MELO}

Universidade Tecnológica Federal do Paraná - Campus Ponta Grossa

E-mail: marcosgervanio@bol.com.br

\section{MARCOS CESAR DANHONI NEVES}

Universidade Tecnológica Federal do Paraná - Campus Ponta Grossa

E-mail: macedane@yahoo.com

\section{SANI DE CARVALHO RUTZ DA SILVA}

Universidade Tecnológica Federal do Paraná - Campus Ponta Grossa

E-mail: sanirutz@gmail.com

\section{RESUMO}

O objetivo desse estudo é analisar os resultados do PISA 2015, na área de ciências, buscando desvelar dados que justifiquem a necessidade de um curso de formação de professores de ciências, vislumbrando melhorar os seus desempenhos no que se refere à promoção da Alfabetização Científica e Tecnológica dos seus alunos. Especificamente, busca-se verificar desempenhos dos alunos brasileiros em relação aos participantes dos demais países, bem como em relação ao comparativo entre os estados da federação, na área de ciências. Os países cujos estudantes apresentaram menor dificuldade, em relação ao conhecimento epistemológico, conseguiram que seus alunos minimizassem as dificuldades em relação aos conhecimentos de conteúdo e procedimental. Assim, a formação inicial do professor de ciências precisa se impregnar de conhecimentos epistemológicos e procedimentais, pois do contrário a ciência continuará sendo trabalhada na escola como se fosse um objeto de descoberta, um conhecimento pronto, acabado, imutável, inquestionável e, principalmente desinteressante.

PALAVRAS-CHAVE:

PISA 2015, área de ciências. conhecimentos epistemológico e procedimental. formação inicial do professor de ciências.

A LOOK AT THE BRAZILIAN RESULTS IN PISA 2015: POSSIBILITIES OF REFLECTING ON PROBLEMS OF SCIENCE TEACHING AND THE INITIAL TRAINING OF THE SCIENCE TEACHER

ABSTRACT: 
The aim of this study is to analyze the results of PISA 2015 in the area of sciences, seeking to unveil data that justify the need for a training course for science teachers, hoping to improve their performance in the promotion of Scientific and Technological Literacy of their students. Specifically, it is sought to verify the performances of Brazilian students in relation to the participants of the other countries, as well as in relation to the comparative among the states of the federation, in the area of sciences. The countries whose students presented less difficulty, in relation to epistemological knowledge, were able to minimize their difficulties in terms of content and procedural knowledge. Thus, the initial formation of the science teacher needs to be impregnated with epistemological and procedural knowledge, otherwise science will continue to be worked on in the school as if it were an object of discovery, a knowledge that is ready, immutable, unquestionable and, above all, uninteresting.

\section{KEYWORDS:}

PISA 2015. area of sciences. epistemological and procedural knowledge. initial formation of the sciences teacher.

\section{INTRODUÇÃO}

Imagine que você se encontra preso numa caverna. Pior que isso, imagine que você nasceu nessa caverna e que o único contato com o exterior da mesma ocorre quando você enxerga as sombras das pessoas e animais, que estão fora da caverna, projetadas na parede do fundo da mesma. Além disso, você também escutaria o som oriundo de fora da caverna, acreditando, no entanto, que este fora produzido pelas sombras. Imaginou? Você percebe, diante disso, que o mundo que se entremostra a você, no interior da caverna, esconde uma realidade que acontece no exterior da mesma? E que se uma pessoa tentar lhe dizer que o som e as sombras estão relacionados a entes fora da caverna, você certamente o chamará de louco e o marginalizará'?

Refletindo sobre a alegoria da caverna de Platão, anteriormente mencionada, pode-se dizer que isso tem alguma influência na educação e, mais especificamente, no ensino de ciências no Brasil? Aproveitando a metáfora, o professor de ciências

\footnotetext{
${ }^{1}$ (PLATÃO, 1999).
} 
estaria preso a um mundo que o cegaria a ponto de não refletir, por exemplo, a quem interessa o ensino de ciências que realiza no cotidiano? Parece que sim. 0 professor tem liberdade para aprofundar qualquer tema científico? Parece que não.

A tentativa de se desvelar a realidade que se esconde por trás do ensino de ciências que se perpetua no Brasil, poderá, certamente, estimular o martelo da opressão a marginalizar a figura do revelador. Mas é preciso, pois essa realidade precisa ser refletida e discutida para que a formação dos professores de ciências possa ser agraciada. Assim, os resultados do PISA 2015 podem oferecer um interessante alicerce para se desvelar realidades e necessidades no ensino de ciências.

Diante disso, esse artigo pretende responder a seguinte questão: como os resultados do PISA 2015, na área de ciências, podem justificar a necessidade de um curso de formação de professores de ciências que vislumbre melhorar os seus desempenhos no que se refere à promoção da Alfabetização Científica e Tecnológica dos seus alunos?

Por disso, o objetivo geral desse estudo é analisar os resultados do PISA 2015, na área de ciências, buscando desvelar dados que justifiquem a necessidade de um curso de formação de professores de ciências, vislumbrando melhorar os seus desempenhos no que se refere à promoção da Alfabetização Científica e Tecnológica dos seus alunos.

Especificamente, busca-se verificar desempenhos dos alunos brasileiros em relação aos participantes dos demais países, bem como em relação ao comparativo entre os estados da federação, na área de ciências. Além disso, pretende-se identificar excertos nos documentos do PISA 2015, na área de ciências, que se articulem às recomendações presentes na literatura de formação de professores de ciências. 
Assim, a leitura dos documentos do PISA 2015, numa perspectiva de análise de conteúdo de Bardin (2011), oferece um interessante caminho para esse estudo.

\section{OLHANDO O ENSINO DE CIÊNCIAS POR BAIXO DO TAPETE}

Seria absurdo falar em inquisição ${ }^{2}$ educacional ou, especificamente, inquisição no ensino de ciências? De acordo com Samuel Ramos Lago, autor de diversos livros de Ciências Naturais para o ensino fundamental, não seria absurdo, mas uma realidade a se refletir, pois o mencionado escritor fora "torturado", tanto por escolas de características confessionais católicas e evangélicas, quanto por escolas com um viés protestante evangélica (LAGO, 2017).

Segundo o autor, algumas dessas escolas deixaram de adotar quatro dos seus livros quando o citado escritor tentou aprofundar as discussões sobre um dos temas transversais, recomendado inclusive por documentos oficiais da educação (BRASIL, 1997,2000, 2002, 2006), a Orientação Sexual, apesar de a intenção ser a de evitar doenças sexualmente transmissíveis e a gravides precoce (LAGO, 2017). É importante dizer que uma das recomendações à formação do professor de ciências consiste em "estar preparado para aprofundar os conhecimentos e adquirir outros novos" (GIL-PÉREZ; CARVALHO, 2009, p. 22).

Porém, a inquisição continua quando o mencionado autor aborda a temática origem da vida e evolução na perspectiva Darwinista ${ }^{3}$ (LAGO, 2017).

\footnotetext{
${ }^{2}$ Criada no interior da Igreja Católica Romana tratava-se de uma instituição jurídica cuja função era combater a heresia, perseguindo, julgando e até punindo os indivíduos que ousassem desviar das recomendações apresentadas pela igreja. A inquisição possuía objetivos ideológicos, além de econômicos e, inclusive, sociais que visavam, entre outras coisas, a manutenção e o controle das praticas religiosas e o combate ao sectarismo religioso (LAGO, 2017).

${ }^{3}$ Recomenda-se assistir o filme "o vento será tua herança" de Stanley Kramer, 1960, EUA como exemplo de situação de inquisição no ensino de ciências. O filme discute um fato ocorrido no Tennessee, EUA, no ano de 1925. O mesmo discorre sobre a condenação de um professor, após julgamento, por ensinar a teoria da evolução de Darwin numa escola pública. O julgamento do macaco foi como ficou registrado o acontecimento. É bom lembrar que aos advogados de defesa não foi permitido usar membros da comunidade científica como testemunhas em favor da teoria da evolução de Darwin.
} 
Na mesma linha de pensamento, o movimento Escola Sem Partido (ESP) que ardilosamente insinua combater as ideologias no interior das escolas, lançando olhares sobre a doutrinação, trabalha, na realidade, para "a retirada do pensamento crítico, da problematização e da possibilidade de se democratizar a escola" (MANHAS, 2016, p.16), isto é, uma conduta que aponta para o cerceamento da liberdade de pensamento, coadunando com os pressupostos da inquisição.

É importante dizer que "11 dos 19 proponentes de projetos inspirados pelo ESP são ligados a alguma igreja" (SAKAMOTO, 2016, p.13). O movimento tem a audácia de recomendar que o professor seja um transmissor de conteúdos desprovidos de criticidade e de problematização, que priorize um processo mecânico e sem contextualização, ameaçando, inclusive, processar professores que trabalhem assuntos de ciências como sexualidade (MANHAS, 2016; SAKAMOTO, 2016), por exemplo. Isso mostra que apesar da ciência ser institucionalizada em nossas escolas, ela atende a interesses que travam o seu desenvolvimento no ambiente escolar.

Sobre isso, é bom ressaltar que "do ponto de vista dos interesses dominantes, não há dúvida de que a educação deve ser uma prática imobilizadora e ocultadora de verdades" (FREIRE, 1996, p. 99).

Assim, oportuniza-se refletirmos sobre a fala de Freire, quando diz que

[...] seria na verdade uma atitude ingênua esperar que as classes dominantes desenvolvessem uma forma de educação que proporcionasse às classes dominadas perceber as injustiças sociais de maneira crítica (FREIRE, 1981, p. 73).

Sobre isso, entende-se que o professor de ciências não faz parte da classe dominante, sendo vítima de um sistema opressor que centraliza sua formação no conteúdo conceitual, quase sempre, com um fim em si mesmo. O pior de tudo não é 
o professor de ciências carecer de uma formação adequada, mas não estar consciente de suas insuficiências (GIL-PÉREZ; CARVALHO, 2009).

Quais insuficiências? De uma formação que inclua, por exemplo, aspectos epistemológicos, bem como históricos e filosóficos concernentes à ciência, além de valorizar também conteúdos procedimentais e atitudinais.

Por outro lado, o modelo de ensino de ciências acrítico, descontextualizado, inquisitivo e, principalmente, reducionista pode metaforicamente ser entendido como uma caverna contemporânea de Platão que aprisiona professores, perpetuando uma cultura que interessa somente as classes oligárquicas. Uma cultura que prioriza, por exemplo, as práticas behavioristas, centrada no ensino do extenso conteúdo, que se entende como transferência de saber, que mitiga a curiosidade do aluno quando o conduz à memorização mecânica do conteúdo e que mais domestica do que forma (FREIRE, 1996).

Diante disso, os resultados catastróficos do PISA 2015, no que se refere ao ensino de ciências no Brasil, podem facilmente ser interpretados na perspectiva fatalista apontada por Freire (1996), surgindo "justificativas" como não se pode fazer nada, pois os alunos têm dificuldades em entender física ou o discurso do professor pragmático dizendo que fez tudo o que podia fazer, deu todo o conteúdo, mas os alunos são "fracos" e não conseguem acompanhar.

Esse discurso fatalista que, quase sempre, surge na tentativa de eximir culpas é, muitas vezes, validado socialmente e acaba servindo de subterfúgio para que o professor de ciências não exerça, sobre sua prática, uma reflexão crítica. Diante disso, recomenda-se a mudança do discurso, acompanhado, inclusive, da mudança de atitude, qual seja: "quanto mais me assumo como estou sendo e percebo a ou as razões de ser de porque estou sendo assim, mais me torno capaz de mudar" (FREIRE, 1996, p.39). 
Tal assunção poderia oportunizar ao professor de ciências uma análise diferente, mais crítica e mais contextualizada, dos resultados do PISA 2015 o levando, inclusive, a uma reflexão mais apropriada sobre algumas indagações como, por exemplo, a quem interessa o ensino de ciências que realizo? o que fazer para me livrar das amarras que me prendem nessa caverna platônica, o modelo tênue de ensino de ciências?

\section{OBSERVANDO O PISA: TECENDO ARGUMENTOS}

O PISA - Programa Internacional de Avaliação de Estudantes, lançado pela OCDE - Organização para a Cooperação e Desenvolvimento Econômico, avalia trienalmente os alunos de 15 anos quando estes chagam no fim da educação obrigatória, focando conhecimentos adquiridos em ciência, matemática e leitura, utilizando também questionários contextuais aplicados não só a estudantes, mas a professores, diretores e inclusive aos pais. O Programa integra um conjunto de avaliações, além de exames nacionais e internacionais que são coordenados pela Diretoria de Avaliação da Educação Básica - DAEB, integrante do Instituto Nacional de Estudos e Pesquisas Educacionais Anísio Teixeira - INEP (BRASIL, 2016).

O PISA é um programa contínuo que se preocupa em investigar, inclusive, o quão bem os alunos podem aplicar os conhecimentos, seja no ambiente escolar ou não, em situações não familiares. Por meio do programa, o Brasil tem como contrastar o desempenho dos nossos alunos em ciências, matemática e leitura com estudantes dos países integrantes da OCDE, bem como de 35 países parceiros, mas os conhecimentos e habilidades dos alunos podem ser monitorados em distintos subgrupos demográficos em cada um dos países (BRASIL, 2016). 
É importante lembrar que o PISA utiliza o termo "letramento científico" ao avaliar competências na área de ciências. Contudo, esse estudo não hesitará em utilizar a denominação "alfabetização científica" por entender que a mesma:

[...] engloba a ideia de letramento, entendida como a capacidade de ler, compreender e expressar opiniões sobre ciência e tecnologia, mas também participar da cultura científica da maneira que cada cidadão, individualmente e coletivamente, considerar oportuno (KRASILCHIK; MARANDINO, 2007, p.18).

Assim, a figura 1 faz um esboço das competências necessárias para uma discussão crítica sobre Ciência e Tecnologia (C\&T), bem como dos conhecimentos exigidos pelos documentos do PISA 2015.

Figura 1: Competências e Conhecimentos Científicos de interesses do PISA. Fonte: autores, adaptado de OECD (2015).

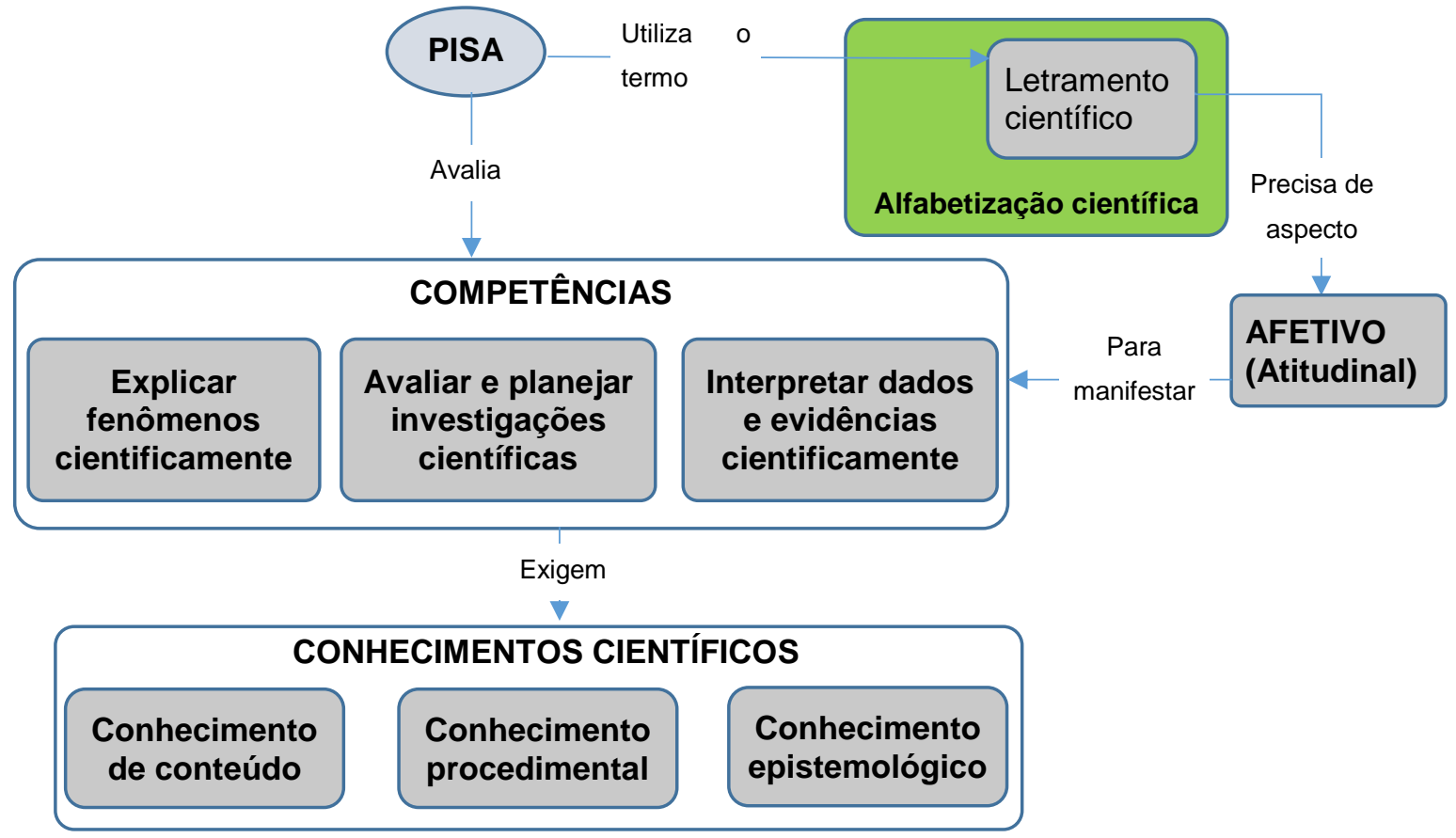

É importante observar o interesse que o PISA confere à avaliação de competências, mas que as mesmas necessitam de saberes científicos que incluem conteúdos procedimentais e epistemológicos, além de valorizarem elementos afetivos como o interesse pela ciência, por exemplo. Contudo, é preciso dizer que 
infelizmente "esta perspectiva difere da de muitos programas de ciências da escola, que são, muitas vezes, dominados por conhecimento de conteúdo" (OECD, 2015, p. $6)$.

Sobre isso, pode-se dizer que:

[...] assim como não posso ser professor sem me achar capacitado para ensinar certo e bem os conteúdos de minha disciplina não posso, por outro lado, reduzir minha prática docente ao puro ensino daqueles conteúdos (FREIRE, 1996, p. 103).

Em outras palavras, não se pode reduzir o ensino de Física, por exemplo, à transmissão e memorização de conteúdos conceituais, desprezando conhecimentos procedimentais e epistemológicos, pois "as pessoas precisam das três formas de conhecimento científico para executar as três competências de letramento científico" (OECD, 2015, p. 6).

Assim, o quadro 1 pode contribuir para uma boa explanação dos mencionados conhecimentos.

Quadro 1 - Conhecimentos necessários para o letramento científico de acordo com o PISA 2015. Fonte: dados organizados pelos autores, com base nas informações de OECD (2015).

\begin{tabular}{|c|c|c|}
\hline Denominação & Descrição & Exemplos \\
\hline \multirow{6}{*}{$\begin{array}{l}\text { Conhecimento de } \\
\text { conteúdo }\end{array}$} & \multirow{6}{*}{$\begin{array}{l}\text { O primeiro e mais familiar, é o } \\
\text { conhecimento de fatos, conceitos, } \\
\text { ideias e teorias sobre o mundo } \\
\text { natural que a ciência estabeleceu. } \\
\text { Engloba conhecimento do mundo } \\
\text { natural, bem como de artefatos } \\
\text { tecnológicos. Envolvem conceitos } \\
\text { científicos ou teorias explicativas } \\
\text { importantes, com utilidades } \\
\text { duradouras, dos principais campos da } \\
\text { física, química, biologia, ciências da } \\
\text { terra e do espaço. }\end{array}$} & Conhecimentos dos sistemas físicos \\
\hline & & $\begin{array}{l}\text { Energia e transformação (conservação, } \\
\text { dissipação, reações químicas). Interações entre } \\
\text { energia e matéria (ondas sonoras e luminosas, } \\
\text { som e ondas sísmicas). Mudanças químicas da } \\
\text { matéria (reações químicas, transferência de } \\
\text { energia, ácidos/bases). }\end{array}$ \\
\hline & & Conhecimentos dos sistemas vivos \\
\hline & & $\begin{array}{l}\text { Células (estrutura e função, DNA). Ecossistemas } \\
\text { (cadeias e teias alimentares, fluxo de matéria e } \\
\text { energia). }\end{array}$ \\
\hline & & Conhecimentos do sistema Terra e Espaço \\
\hline & & $\begin{array}{l}\text { Estruturas do sistema Terra (litosfera, hidrosfera, } \\
\text { atmosfera). Energia no sistema Terra (fontes, } \\
\text { clima global). }\end{array}$ \\
\hline
\end{tabular}




\begin{tabular}{|c|c|c|}
\hline $\begin{array}{l}\text { Conhecimento } \\
\text { procedimental }\end{array}$ & $\begin{array}{l}\text { É o conhecimento de como as ideias que } \\
\text { formam a base do conhecimento científico } \\
\text { são produzidas. O conhecimento dos } \\
\text { procedimentos padrões que embasam os } \\
\text { diversos métodos e práticas utilizadas na } \\
\text { investigação científica para estabelecer o } \\
\text { conhecimento científico. Este é um } \\
\text { conhecimento das práticas e conceitos em } \\
\text { que se fundamenta a investigação empírica, } \\
\text { como a repetição de medidas para minimizar } \\
\text { erros e reduzir a incerteza, o controle de } \\
\text { variáveis e os procedimentos padrões para } \\
\text { representar e apresentar dados. Assim, é } \\
\text { essencial para a investigação científica que } \\
\text { sustenta a coleta, análise e interpretação de } \\
\text { dados científicos. }\end{array}$ & $\begin{array}{l}\text { - Conceitos de variáveis dependentes e } \\
\text { independentes; } \\
\text { - Conceitos de medidas: qualitativas e } \\
\text { quantitativas, escalas, variáveis contínuas e } \\
\text { discretas; } \\
\text { - Formas de avaliar e minimizar incertezas: } \\
\text { repetições, medidas médias; } \\
\text { - Mecanismos de geração de replicabilidade; } \\
\text { Ferramentas de representação de dados: } \\
\text { gráficos, tabelas, mapas, histogramas; } \\
\text { - Controle de variáveis: desenho experimental, } \\
\text { randomização; } \\
\text { - Natureza de desenhos específicos: observação, } \\
\text { busca de padrões, experimentação. }\end{array}$ \\
\hline \multirow[b]{3}{*}{$\begin{array}{l}\text { Conhecimento } \\
\text { epistemológico }\end{array}$} & \multirow{3}{*}{$\begin{array}{l}\text { É um conhecimento de construtos e } \\
\text { características definidoras essenciais para o } \\
\text { processo de construção do conhecimento em } \\
\text { ciência e do seu papel na justificativa do } \\
\text { conhecimento produzido pela ciência, por } \\
\text { exemplo, uma hipótese, uma teoria ou uma } \\
\text { observação e sua contribuição para a forma } \\
\text { como nós sabemos o que sabemos. Explica a } \\
\text { distinção entre uma teoria científica e uma } \\
\text { hipótese ou um fato científico e uma } \\
\text { observação. Tal conhecimento revela que a } \\
\text { construção de modelos, sejam eles } \\
\text { diretamente representativos, abstratos ou } \\
\text { matemáticos, é uma característica } \\
\text { fundamental da ciência e que tais modelos } \\
\text { são semelhantes aos mapas em vez de } \\
\text { imagens precisas do mundo material. }\end{array}$} & $\begin{array}{l}\text { Os construtos e recursos das ciências } \\
\text { - Natureza das observações científicas, fatos, } \\
\text { hipóteses, modelos e teorias; } \\
\text { - Propósitos e objetivos das observações } \\
\text { científicas: produção de explicações do mundo } \\
\text { natural, produção de soluções para as } \\
\text { necessidades humanas (tecnologia); } \\
\text { - Valores da ciência: compromisso, objetividade, } \\
\text { eliminação de viés; } \\
\text { - Natureza do raciocínio científico: dedução, } \\
\text { indução, inferência, analogias e uso de modelos. }\end{array}$ \\
\hline & & $\begin{array}{l}\text { O papel dos construtos e recursos para justificar a } \\
\text { produção do conhecimento científico }\end{array}$ \\
\hline & & $\begin{array}{l}\text { - Como afirmações científicas são apoiadas por } \\
\text { dados e raciocínio na ciência; } \\
\text { - Função das diferentes formas de investigação } \\
\text { para produção de conhecimentos; } \\
\text { - Como as medidas de erro afetam o grau de } \\
\text { confiabilidade do conhecimento científico; } \\
\text { - Uso e limites de uso dos modelos físicos, } \\
\text { sistêmicos e abstratos; } \\
\text { - Papel dos pares no estabelecimento de } \\
\text { confiabilidade nas comunidades científicas; } \\
\text { - Papel do conhecimento científico e de outras } \\
\text { formas de conhecimento na identificação de } \\
\text { questões sociais e tecnológicas. }\end{array}$ \\
\hline
\end{tabular}

Pode-se observar que a concentração dos trabalhos dos professores de ciências no conhecimento de conteúdos representa, na realidade, um dos graves problemas da Educação em Ciências, pois a "falta de conhecimentos científicos ${ }^{4}$

\footnotetext{
${ }^{4}$ Precisam incluir as dimensões procedimentais e epistemológicas e, não somente, os conhecimentos de conteúdo.
} 
constitui a principal dificuldade para professores afetados se envolverem em atividades inovadoras" (GIL-PÉREZ; CARVALHO, 2009, p. 21).

Diante disso, para se valorizar os conhecimentos procedimental e epistemológico, seria interessante ensinar ciências buscando fazer ciências, pois, assim, criar-se-ia a oportunidade da construção de uma visão mais apropriada da ciência, bem como dos cientistas e dos seus trabalhos com acertos e desacertos (CARVALHO; SASSERON, 2010). Para isso, é necessário se pensar a formação do professor numa perspectiva que amplie o seu contato com o conhecimento científico em detrimento de uma preparação, por exemplo, que intensifique a cultura de "um educador com muito pouco de formador, com muito mais de treinador, de transferidor de saberes, de excitador de destrezas" (FREIRE, 1996, p. 143), ou seja, uma formação docente que parece mais atender aos interesses daqueles que temem uma educação progressista e libertadora.

Assim, o quadro 2 apresenta uma interessante sistematização dos aspectos que revelam a amplitude da matéria a ser ensinada, refletindo sua importância para a formação do professor de ciências.

Quadro 2 - Conhecer a matéria a ser ensinada. Fonte: Gil-Pérez e Carvalho (2009, p. 22).

A. Conhecer os problemas que originaram a construção dos conhecimentos científicos (sem o que os referidos conhecimentos surgem como construções arbitrárias). Conhecer, em especial, quais foram as dificuldades e obstáculos epistemológicos (o que constitui uma ajuda imprescindível para compreender as dificuldades dos alunos).

B. Conhecer as orientações metodológicas empregadas na construção dos conhecimentos, a forma como os cientistas abordam os problemas, as características mais notáveis de sua atividade, os critérios de validação e aceitação das teorias científicas.

C. Conhecer as interações Ciência/Tecnologia/sociedade associada à referida construção, sem ignorar o caráter, em geral, dramático, do papel social das Ciências; a necessidade da tomada de decisões.

D. Ter algum conhecimento dos desenvolvimentos científicos recentes e suas perspectivas, para poder transmitir uma visão dinâmica, não fechada, da Ciência. Adquirir, do mesmo modo, conhecimento de outras matérias relacionadas, para poder abordar problemas afins, as interações entre os diferentes campos e os processos de unificação.

E. Saber selecionar conteúdos adequados que dêem uma visão correta da Ciência e que sejam acessíveis aos alunos e suscetíveis de interesse.

F. Estar preparado para aprofundar os conhecimentos e para adquirir outros novos. 
Diante disso, pode-se observar que o discurso que ressalta que "o professor precisa saber o conteúdo para ensinar ciências" precisa ter, nesse professor, um discernimento suficiente para que não o interprete numa perspectiva reducionista que contemple apenas o conhecimento de conteúdo. Isso parece revelar que "o saber escolar é também, e sobretudo, um saber político" (CHASSOT, 2011, p. 214) que pode ser selecionado na intenção de se manter um grupo dominante. Um conteúdo que pode ser priorizado para favorecer um processo behaviorista que mitiga a possibilidade do pensar no ensino de ciências e estimula ações de condicionamento dos alunos.

No entanto, o conceito de conteúdo escolar vem sofrendo exigências que transcendem a utilização do conteúdo conceitual ${ }^{5}$, pois, além dele, recomendam-se os procedimentais ${ }^{6}$, bem como as dimensões atitudinais (CARVALHO, 2009). Esse aspecto atitudinal também aparece nas recomendações dos documentos do PISA, mas o que seria, então, tais elementos afetivos mencionados nos citados documentos?

Para iniciar um contato com o aspecto atitudinal, é bom saber que muitos alunos, do segundo grau escolar, aprendem desde cedo a não se interessar por Física e, se pudessem, infelizmente, evitariam tal matéria (MOREIRA, 1983). É exatamente o interesse pela ciência e tecnologia que constitui uma das áreas avaliadas pelo PISA 2015 no que se refere às atitudes dos estudantes referentes à ciência (OECD, 2015). O quadro 3 esboça as áreas consideradas fundamentais ao letramento científico.

\footnotetext{
${ }^{5}$ Nos documentos do PISA 2015, representa o conhecimento de conteúdo, também chamada de conhecimento de conteúdo de ciências.

${ }^{6}$ Nessa perspectiva de se pensar o conhecimento científico a ser trabalhado na escola dividido em conteúdo conceitual, procedimental e atitudinal, a dimensão epistemológica, mencionada nos documentos do PISA, não desaparece, mas se dilui principalmente no aspecto procedimental.
} 


\section{Quadro 3 - Áreas fundamentais à construção do letramento científico relacionadas à avaliação de atitude. Fonte: dados organizados pelos autores, com base nas informações de OECD (2015).}

\begin{tabular}{|c|c|c|}
\hline Áreas & Indicadores dessa atitude & Construtos utilizados na verificação \\
\hline $\begin{array}{l}\text { Interesses por } \\
\text { Ciência e } \\
\text { Tecnologia }\end{array}$ & $\begin{array}{l}\text { • Curiosidade em ciências e } \\
\text { assuntos relacionados com as } \\
\text { ciências e seus empenhos; } \\
\text { • Desejo de adquirir } \\
\text { conhecimentos e habilidades } \\
\text { adicionais em ciências, utilizando } \\
\text { recursos e métodos variados; } \\
\text { • Interesse crescente em } \\
\text { ciências, incluindo a } \\
\text { consideração de seguir uma } \\
\text { carreira científica. }\end{array}$ & $\begin{array}{l}\text { Interesse em aprender ciências: uma medida de quanto de } \\
\text { interesse os estudantes têm em aprender sobre física, } \\
\text { biologia humana, geologia e os processos e produtos da } \\
\text { investigação científica. } \\
\text { Satisfação com ciências: uma medida de quanto os alunos } \\
\text { gostam de aprender sobre ciências, tanto dentro como fora } \\
\text { da escola. Futuro orientado para atividades em ciências: uma } \\
\text { medida do nível de desejo dos estudantes em seguir carreira } \\
\text { científica ou estudo de ciências depois da escola. Motivação } \\
\text { instrumental para aprender: uma medida de quanto da } \\
\text { motivação dos estudantes para aprender a ciência é } \\
\text { extrinsecamente motivada pelas oportunidades que as } \\
\text { ciências oferecem para o emprego. Valor geral das ciências: } \\
\text { uma medida da quantidade de prestígio que o estudante dá } \\
\text { a uma gama de diferentes carreiras, incluindo as científicas. } \\
\text { Auto-eficácia em ciências: uma medida de quão capaz o } \\
\text { estudante percebe-se em relação a ciências. O prestígio } \\
\text { ocupacional de carreiras específicas: uma medida do valor } \\
\text { que o estudante dá para a ciência para si mesmo. Uso da } \\
\text { Tecnologia: uma escala que mede como os adolescentes } \\
\text { utilizam as novas tecnologias. Experiências em ciências fora } \\
\text { da escola: uma medida das atividades extracurriculares de } \\
\text { ciências com as quais os estudantes se envolvem. Aspirações } \\
\text { de carreira: uma ampla medida da disposição que os } \\
\text { estudantes têm para as carreiras científicas. Preparação da } \\
\text { escola para a carreira em ciências: uma medida de quão bem } \\
\text { o estudante se sente em relação à educação científica formal } \\
\text { fornecida por sua escola, ou seja, dos conhecimentos e } \\
\text { habilidades necessárias para uma carreira científica. } \\
\text { Informação que o estudante tem sobre as carreiras em } \\
\text { ciências: uma medida de quão bem informado o estudante } \\
\text { se sente sobre as possíveis carreiras científicas. } \\
\end{array}$ \\
\hline $\begin{array}{c}\text { Consciência } \\
\text { ambiental }\end{array}$ & $\begin{array}{l}\text { - Uma preocupação com o meio } \\
\text { ambiente e a vida sustentável; } \\
\text { - Uma disposição de assumir e } \\
\text { promover comportamentos } \\
\text { ambientalmente sustentáveis. }\end{array}$ & $\begin{array}{l}\text { Sensibilização para as questões ambientais: uma medida de } \\
\text { como os estudantes são informados sobre as questões } \\
\text { ambientais atuais. Percepção das questões ambientais: uma } \\
\text { medida de quanto os estudantes se preocupam com } \\
\text { questões ambientais. Otimismo ambiental: uma medida de } \\
\text { crença dos estudantes sobre a contribuição de suas ações ou } \\
\text { de outros para a manutenção e melhoria do ambiente. }\end{array}$ \\
\hline $\begin{array}{l}\text { Valorização de } \\
\text { abordagens } \\
\text { científicas na } \\
\text { pesquisa }\end{array}$ & $\begin{array}{c}\text { - Um compromisso de que a } \\
\text { evidência é a base da crença } \\
\text { para as explicações sobre o } \\
\text { mundo material; } \\
\text { • Um compromisso com o } \\
\text { enfoque na pesquisa científica, } \\
\text { quando for o caso; } \\
\text { • Uma valorização da crítica } \\
\text { como um meio de estabelecer a } \\
\text { validade de qualquer ideia. }\end{array}$ & $\begin{array}{c}\text { As atitudes dos alunos em relação ao uso de um método } \\
\text { científico para investigar o fenômeno social e as ideias } \\
\text { derivadas de tais métodos. }\end{array}$ \\
\hline
\end{tabular}


Recorrendo-se à figura 1, é possível entender que os aspectos afetivos, observados no quadro 3, são importantíssimos para que o indivíduo letrado cientificamente possa manifestar competências em relação à C\&T. Contudo, a dimensão atitudinal parece ser muito prejudicada na escola, pois a cultura behaviorista que coloca o professor como elemento principal do processo ensinoaprendizagem e relega o aluno à passividade, à memorização, ao condicionamento, contribui fortemente para que esse aluno não se interesse por assuntos relacionados à C\&T.

Além disso, ao se priorizar um ensino centrado apenas no conhecimento de conteúdo, em detrimento dos conhecimentos procedimentais e epistemológicos, na escola, contribui-se fortemente para a concepção "bancária" de educação, pois se utiliza "conteúdos que são retalhos da realidade desconectados da totalidade em que se engendram [...] que o educando fixa, memoriza, repete, sem perceber o que realmente significa" (FREIRE, 1987, p. 33).

Assim, parece fácil perceber que o extenso, porém, parco conteúdo escolar compreende, indubitavelmente, a parcela do conhecimento científico que mais favorece um ensino alienante, desprovido de transformação, de criatividade, de saber, que estimula ações em que o educador revela-se o sujeito pensante, aquele que atua, enquanto o educando entremostra-se um objeto que recebe, memoriza, repete e se adapta, pois é, fortemente, tolhido de criticidade e de conscientização.

Por que, então, não se busca intensificar a inserção das dimensões procedimentais e epistemológicas no conteúdo escolar? Porque, entre outras coisas, parece não interessar aos opressores. Não é interessante à classe dominante que se promova um ensino que desvele o mundo. Não interessa inserir um conteúdo que desloque o educando da condição de objeto à de sujeito. Não interessa estimular a criticidade e a conscientização, para que estas se voltem contra decisões daqueles 
que oprimem. É importante lembrar que há um forte componente político na escolha dos conteúdos escolares, pois a classe opressora, que precisa se manter no controle, entremostra que “a questão está em que, pensar autenticamente, é perigoso" (FREIRE, 1987, p. 35).

Diante disso, cabe ressaltar que seria interessante que professores de ciências buscassem promover um ensino em que se oportunizasse, ao estudante, atuar na construção e reconstrução do conteúdo conceitual (CACHAPUZ et al., 2011) como elemento ativo e participativo do:

[...] processo de construção e dando oportunidade de aprenderem a argumentar e exercitar a razão, em vez de fornece-lhes respostas definitivas ou impor-lhes seus próprios pontos de vista transmitindo uma visão fechada das ciências (CARVALHO, 2009, p. 3).

Por isso, os resultados dos PISA 2015, no que se refere ao ensino de ciências, podem proporcionar um interessante parâmetro de reflexão à priorização da dimensão conceitual do conhecimento científico, isto é, uma oportunidade de se pensar às consequências da visão reducionista que mitiga procedimentos, epistemologia e atitudes no ensino de ciências.

\section{ANALISANDO O PISA 2015: RESULTADOS E DISCUSSÕES}

Como o Brasil participou de todas as edições avaliativas do PISA, sendo o único país sul-americano, seria interessante observar o quadro 4, pois o mesmo mostra os instrumentos avaliados e esboça que a área foco de avaliação de 2015, última edição, foi a de ciências. Por isso, tal edição representa a base das informações desse estudo. 
Quadro 4 - Instrumentos avaliados no Brasil com destaque para a área foco de cada edição. Fonte: dados da OCDE, INEP (BRASIL, 2016, p. 19).

\begin{tabular}{|c|c|c|c|c|c|c|}
\hline PISA & 2000 & 2003 & 2006 & 2009 & 2012 & 2015 \\
\hline \multirow{3}{*}{ 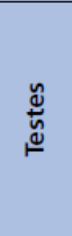 } & Leitura & Leitura & Leitura & Leitura & Leitura & Leitura \\
\hline & Matemática & Matemática & Matemática & Matemática & Matemática & Matemática \\
\hline & & & & & & $\begin{array}{l}\text { Resolução colaborativa } \\
\text { de problemas }\end{array}$ \\
\hline \multirow{3}{*}{ 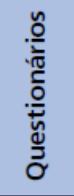 } & Escola & Escola & Escola & Escola & Escola & Escola \\
\hline & & & & & & $\begin{array}{l}\text { Estudante - Familiaridade } \\
\text { com tecnologia }\end{array}$ \\
\hline & & & & & & Professor \\
\hline
\end{tabular}

É possível observar que a primeira vez em que a área de ciências se constituiu como área foco das avaliações, aconteceu em $2006^{7}$. Porém, somente em 2015, os professores passam a participar das mesmas.

O quadro 5 apresenta um panorama brasileiro do quantitativo de distribuição das 841 escolas e dos 23.141 alunos que participaram da avaliação em 2015, bem como a quantidade de professores que ministraram aulas em 2015 nas escolas que foram selecionadas.

Quadro 5 - Quantitativo de escolas, professores e estudantes da amostra efetiva por unidade da Federação - PISA 2015. Fonte: dados da OCDE, INEP (BRASIL, 2016, p. 32).

\begin{tabular}{|c|c|c|c|c|c|c|c|c|c|}
\hline \multirow[t]{2}{*}{ UF } & \multirow[t]{2}{*}{ Escolas } & \multicolumn{2}{|c|}{ Professores } & \multirow{2}{*}{$\begin{array}{l}\text { Estudantes } \\
\text { participantes }\end{array}$} & \multirow[t]{2}{*}{ UF } & \multirow[t]{2}{*}{ Escolas } & \multicolumn{2}{|c|}{ Professores } & \multirow{2}{*}{$\begin{array}{l}\text { Estudantes } \\
\text { participantes }\end{array}$} \\
\hline & & Ciências & Outras & & & & Ciências & Outras & \\
\hline AC & 29 & 89 & 237 & 914 & PB & 32 & 94 & 179 & 749 \\
\hline $\mathrm{AL}$ & 27 & 62 & 139 & 756 & PR & 21 & 41 & 77 & 517 \\
\hline $\mathrm{AP}$ & 21 & 51 & 124 & 482 & $\mathrm{PE}$ & 32 & 116 & 263 & 840 \\
\hline AM & 25 & 82 & 163 & 816 & $\mathrm{PI}$ & 32 & 47 & 119 & 713 \\
\hline BA & 34 & 77 & 165 & 1018 & $\mathrm{RJ}$ & 31 & 149 & 253 & 758 \\
\hline $\mathrm{CE}$ & 35 & 148 & 214 & 934 & $\mathrm{RN}$ & 33 & 64 & 137 & 848 \\
\hline DF & 28 & 103 & 152 & 907 & RS & 35 & 121 & 232 & 900 \\
\hline ES & 31 & 122 & 167 & 911 & RO & 26 & 92 & 266 & 781 \\
\hline $\mathrm{GO}$ & 30 & 64 & 125 & 839 & RR & 26 & 91 & 185 & 801 \\
\hline MA & 30 & 73 & 85 & 770 & SC & 34 & 105 & 270 & 870 \\
\hline MT & 30 & 122 & 251 & 754 & $\mathrm{SP}$ & 66 & 303 & 586 & 2037 \\
\hline
\end{tabular}

\footnotetext{
${ }^{7}$ Nessa edição, o termo conhecimento científico desdobrou-se em dois elementos: o conhecimento de ciências e o conhecimento sobre ciências. Contudo, somente em 2015 o conhecimento sobre ciências se apresenta dividido em dois componentes, quais sejam: os conhecimentos procedimental e epistemológico.
} 


\begin{tabular}{|l|l|l|l|l|l|l|l|l|l|}
\hline MS & 30 & 92 & 288 & 829 & SE & 32 & 82 & 163 & 707 \\
\hline MG & 36 & 181 & 369 & 1101 & TO & 28 & 101 & 243 & 837 \\
\hline PA & 27 & 58 & 105 & 752 & BR & 841 & 2.730 & 5.557 & 23.141 \\
\hline
\end{tabular}

Pode-se observar que os estados do Amapá e Paraná apresentaram baixa representatividade de estudantes na edição do PISA 2015 quando comparados com os demais estados da Federação.

O quadro 6 esboça um comparativo dos resultados dos estudantes brasileiros com os alunos dos 13 países da escala do PISA 2015 e mostra o desempenho médio dos jovens brasileiros por unidade da Federação.

Quadro 6 - Desempenho médio dos estudantes, ciências - PISA 2015. Fonte: dados da OCDE, INEP (BRASIL, 2016, p. 85-87).

\begin{tabular}{|c|c|c|c|c|c|c|c|c|}
\hline \multirow[t]{2}{*}{ UF } & \multirow[t]{2}{*}{ Média } & \multirow[t]{2}{*}{ UF } & \multirow[t]{2}{*}{ Média } & \multirow[t]{2}{*}{ Países $^{8}$} & \multirow[t]{2}{*}{ Média } & \multicolumn{3}{|c|}{ Escolas $^{9}$} \\
\hline & & & & & & & Capital & Interior \\
\hline ES & 435 & MT & 396 & Finlândia & 531 & Média & 412 & 397 \\
\hline $\mathrm{DF}$ & 426 & RJ & 392 & Canadá & 528 & & & \\
\hline PR & 425 & RO & 387 & Coreia do Sul & 516 & & & \\
\hline MG & 422 & PA & 386 & Portugal & 501 & & Federal & Particular \\
\hline SC & 418 & $\mathrm{PE}$ & 383 & Estados Unidos & 496 & Média & 517 & 487 \\
\hline RS & 411 & AP & 381 & Espanha & 493 & & & \\
\hline SP & 409 & $\mathrm{PI}$ & 380 & Chile & 447 & & & \\
\hline GO & 409 & PB & 380 & Uruguai & 435 & & Estadual & Municipal \\
\hline MS & 403 & $\mathrm{RN}$ & 377 & Costa Rica & 420 & Média & 394 & 329 \\
\hline $\mathrm{CE}$ & 401 & SE & 375 & Colômbia & 416 & \multirow{5}{*}{\multicolumn{3}{|c|}{$\begin{array}{l}\text { Notas: } \\
\text { Outras informações como: estimativa de } \\
\text { erro-padrão e intervalo de confiança da } \\
\text { média, além de intervalo interdecil se } \\
\text { encontram na fonte dos dados. }\end{array}$}} \\
\hline BR & 401 & TO & 372 & México & 416 & & & \\
\hline AM & 399 & MA & 369 & Brasil $^{10}$ & 401 & & & \\
\hline$A C$ & 399 & $\mathrm{BA}$ & 368 & Peru & 397 & & & \\
\hline \multirow[t]{4}{*}{ RR } & 398 & $\mathrm{AL}$ & 360 & República Dominicana & 332 & & & \\
\hline & \multicolumn{8}{|c|}{ Países com resultados superiores à média dos da OCDE. } \\
\hline & \multicolumn{8}{|c|}{ Países que se destacaram por apresentar resultados próximos aos dos membros da OCDE. } \\
\hline & & & & c & & & & \\
\hline
\end{tabular}

${ }^{8}$ Além do Brasil, apresentam-se os 13 países escolhidos na escala de interpretação do PISA 2015. Contudo, 70 países/economias participaram das avaliações do PISA 2015 (BRASIL, 2016).

${ }^{9}$ É oportuno observar um desempenho médio dos estudantes da rede federal acima daqueles das escolas particulares, bem como das escolas das capitais com nota média acima daquelas do interior.

${ }^{10}$ Considerando todos os participantes do PISA 2015, o desempenho do Brasil o posicionou na sexagésima terceira posição num total de 70 países/economias. Ficaram abaixo do Brasil somente: Peru, Líbano, Tunísia, FYROM, Kosovo, Argélia e Republica Dominicana. 
Pode-se verificar que a nota média dos estudantes brasileiros de 15 anos foi de 401 pontos $^{11}$ e que os nossos jovens tiveram desempenho abaixo dos estudantes de países da América Latina como México, Colômbia e Costa Rica. Além disso, mesmo os estados que alcançaram resultados acima da média nacional como Espirito Santo, Distrito Federal e Paraná ${ }^{12}$, por exemplo, obtiveram desempenhos médios inferiores quando comparados ao Chile. Porém, as discrepâncias dos comportamentos se acentuam se compararmos o desempenho dos jovens brasileiros ao dos estudantes da Finlândia que obtiveram média de acerto de 531 pontos.

O que, então, poderia justificar esse desempenho dos estudantes brasileiros muito abaixo do desejado na área de ciências? Entre os problemas que assolam o ensino de ciências desde o nível fundamental até o superior, pode-se destacar o estímulo à divisão dos saberes em que o conteúdo conduz as ações contribuindo para uma concepção de ciência como descoberta cuja essência passa a se assemelhar à fé, pois os currículos escolares são construídos numa perspectiva cartesiana que "aniquila a possibilidade da construção do conhecimento" (DANHONI NEVES, 1998, p.74).

Diante disso, "o conhecimento científico, construção sofisticada e gradual da mente humana, passa a ser tomado como algo passível de mera transmissão, de revelação e não como conhecimento a ser elaborado" (CASTRO, 2016, p.30).

Com isso, a educação científica, cujo professor pouco se envolve com aspectos epistemológicos (ALABARRACÍN; NARDI, 2016), trata de difundir e eternizar os

\footnotetext{
${ }^{11} \mathrm{O}$ desempenho dos jovens brasileiros manteve-se no mesmo patamar desde 2006. As médias de 2006, 2009 e 2012 foram respectivamente 390, 405 e 402 (BRASIL, 2016).

${ }^{12}$ O estado do Paraná se comparado aos 70 países/economias participantes do PISA 2015, ocuparia uma posição entre a quinquagésima segunda e terceira, ocupadas por Turquia e Trinidade e Tobago com nota média de 425 pontos, cada um.
} 
[...] paradigmas da ciência por processos de repetição, memória e esquematizações excessivas, através de uma linguagem matemática muitas vezes eclipsadoras do conjunto de fenômenos que deu origem a determinadas teorias e modelos (DANHONI NEVES, 1998, p.79).

Assim, acaba-se dificultando o entendimento do conhecimento cientifico pelos alunos.

A avaliação do PISA 2015 contribuiu para se fazer um comparativo das dificuldades dos estudantes em relação ao conhecimento científico. A figura 2 mostra os itens de ciências e confronta as dificuldades dos alunos em relação aos conhecimentos conceituais, epistemológicos e procedimentais.

Figura 2 - Dificuldade dos itens de ciências segundo conhecimento por país e unidade da Federação - PISA 2015. Fonte: Fonte: dados da OCDE, INEP (BRASIL, 2016, p. 54).

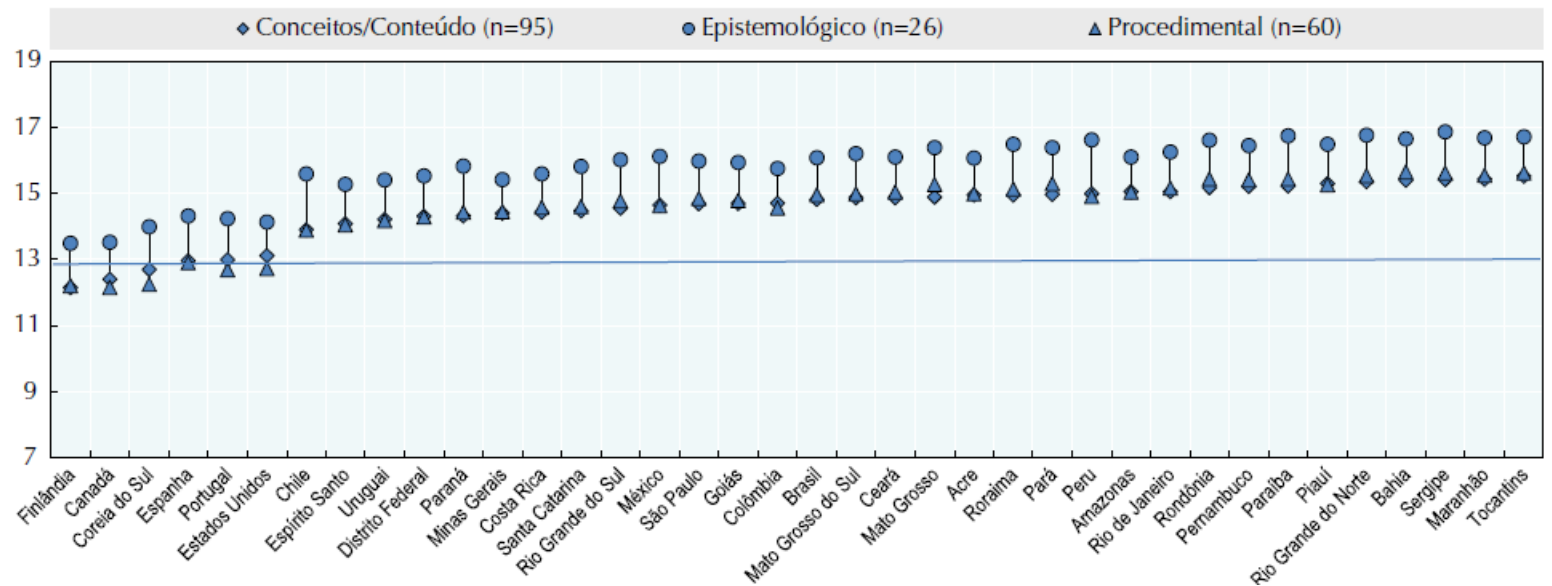

Observando o valor de referência ${ }^{13}$ (Delta igual a 13 ) na figura 2, é possível perceber que até para os estudantes de países como Finlândia e Canadá, que apresentaram melhor desempenho, o Delta de conhecimento epistemológico ficou acima do valor de referência. Porém, tais dificuldades ficaram bem abaixo de 15 . Por outro lado, no Brasil a dificuldade média nos itens de conhecimento epistemológico foi de 16,08, mas há estados que se distanciam desse valor, apresentando acentuada

\footnotetext{
${ }^{13}$ Corresponde a $50 \%$ de acertos.
} 
dificuldade em ralação ao conhecimento epistemológico, como Sergipe, por exemplo.

Enquanto a maior média de acertos dos estudantes brasileiros foi de $32,6 \%$ para os itens abordando conhecimento de conteúdo, a menor se concentrou nos itens de conhecimentos epistemológico com media de acerto de 22,1\% (BRASIL, 2016).

Diante disso, é interessante dizer que um ensino de ciências mais preocupado com a epistemologia poderia proporcionar aos atores um conhecimento sobre teorias concernentes à natureza de ciência, como o indutivismo e falsificacionismo, por exemplo, compreendendo suas forças e inadequações, oportunizando assim refletir "até onde nossas teorias podem ser construídas como uma busca de descrições 'verdadeiras' do que o mundo 'realmente' parece” (CHALMERS, 1993, p. 16).

Assim, no conteúdo epistemológico dar-se-ia condições de se construir concepções mais adequadas sobre o conhecimento científico se expondo, por exemplo, que "não há um método científico fechado, o que vai contra uma visão rígida da ciência, no qual se apresenta no ensino o 'Método Científico' como um conjunto de etapas a se seguir mecanicamente" (NASCIMENTO, 2009, p. 37), estimulando-se um ensino caracterizado por adaptação e ajustamento do indivíduo, bem como sua passividade (FREIRE, 1987).

Um aspecto que chama atenção, na figura 2, é que todos os países que apresentam dificuldades abaixo do valor 15, em relação ao conhecimento epistemológico (desde a Finlândia até os Estados Unidos), conseguiram que seus estudantes minimizassem as dificuldades em relação aos conhecimentos de conteúdo e procedimental. Os estudantes da Finlândia, Canadá e Coreia do Sul que aparecem com a menor dificuldade em relação ao conhecimento epistemológico, 
coincidentemente conseguiram apresentar dificuldade abaixo do valor de referência 13 para os conteúdos conceituais e procedimentais, o que mostra a importância do conhecimento epistemológico no ensino de ciências.

Segundo Cachapuz Et al. (2011) a epistemologia constitui uma teia de relações, quase sempre oculta, mas necessária a educação científica, pois compreende como objeto de conhecimento "a reflexão sobre a produção da ciência, sobre seus fundamentos e métodos, sobre seu crescimento, sobre os contextos de descoberta" (p. 70), ou seja, elementos extremamente importantes ao avanço necessário no ensino das ciências.

Esse aspecto pode ser interessante para se analisar o nível de proficiência dos estudantes na área de ciências. A figura 3 apresenta um esboço do percentual de alunos por nível ${ }^{14}$ de proficiência, em cada país, nos dois anos cuja área de ciências se constitui como foco das avaliações.

Figura 3 - Percentual de estudantes por nível de proficiência, países selecionados, ciências PISA 2006-2015. Fonte: dados da OCDE, INEP (BRASIL, 2016, p. 84).

\begin{tabular}{|c|c|c|c|c|c|c|c|c|c|c|c|c|c|c|}
\hline Ano & Niveis & $\begin{array}{l}\text { Coreia } \\
\text { do Sul }\end{array}$ & Canadá & Finlândia & Portugal & Espanha & $\begin{array}{l}\text { Estados } \\
\text { Unidos }\end{array}$ & $\begin{array}{l}\text { Costa } \\
\text { Rica }^{1,2}\end{array}$ & Chile & Uruguai & México & Colômbia & Peru' 1 & Brasil \\
\hline \multirow{7}{*}{ ஜ } & $<1$ & 2,5 & 2,2 & 0,5 & 5,8 & 4,7 & 7,6 & - & 13,1 & 16,7 & 18,2 & 26,2 & - & 27,9 \\
\hline & 1 & 8,7 & 7,8 & 3,6 & 18,7 & 14,9 & 16,8 & - & 26,7 & 25,4 & 32,8 & 34,0 & - & 33,1 \\
\hline & 2 & 21,2 & 19,1 & 13,6 & 28,8 & 27,4 & 24,2 & - & 29,9 & 29,8 & 30,8 & 27,2 & - & 23,8 \\
\hline & 3 & 31,8 & 28,8 & 29,1 & 28,8 & 30,2 & 24,0 & - & 20,1 & 19,7 & 14,8 & 10,6 & - & 11,3 \\
\hline & 4 & 25,5 & 27,7 & 32,2 & 14,7 & 17,9 & 18,3 & - & 8,4 & 6,9 & 3,2 & 1,9 & - & 3,4 \\
\hline & 5 & 9,2 & 12,0 & 17,0 & 3,0 & 4,5 & 7,5 & - & 1,8 & 1,3 & 0,3 & 0,2 & - & 0,5 \\
\hline & 6 & 1,1 & 2,4 & 3,9 & 0,1 & 0,3 & 1,5 & - & 0,1 & 0,1 & 0,0 & 0,0 & - & 0,0 \\
\hline \multirow{8}{*}{$\stackrel{\sim}{\circ}$} & $<1$ & 0,4 & 0,1 & 0,3 & 0,2 & 0,3 & 0,5 & 0,7 & 1,0 & 1,2 & 1,1 & 1,7 & 2,8 & 4,4 \\
\hline & $1 \mathrm{~B}^{4}$ & 2,9 & 1,8 & 2,3 & 3,2 & 3,7 & 4,3 & 10,1 & 8,9 & 11,2 & 11,7 & 14,5 & 19,0 & 19,9 \\
\hline & $1 \mathrm{~A}^{3}$ & 11,1 & 9,1 & 8,9 & 14,0 & 14,3 & 15,5 & 35,6 & 25,0 & 28,4 & 35,0 & 32,8 & 36,7 & 32,4 \\
\hline & 2 & 21,7 & 20,2 & 19,1 & 25,4 & 26,5 & 25,5 & 35,5 & 31,0 & 30,3 & 34,7 & 30,6 & 27,9 & 25,4 \\
\hline & 3 & 29,2 & 30,3 & 29,2 & 28,8 & 31,3 & 26,6 & 15,2 & 23,8 & 20,3 & 15,1 & 15,9 & 11,5 & 13,1 \\
\hline & 4 & 24,0 & 26,1 & 26,0 & 21,0 & 18,9 & 19,1 & 2,7 & 9,1 & 7,4 & 2,3 & 4,1 & 2,0 & 4,2 \\
\hline & 5 & 9,2 & 10,4 & 11,9 & 6,7 & 4,7 & 7,3 & 0,1 & 1,2 & 1,2 & 0,1 & 0,3 & 0,1 & 0,6 \\
\hline & 6 & 1,4 & 2,0 & 2,4 & 0,7 & 0,3 & 1,2 & - & 0,0 & 0,1 & - & - & - & 0,0 \\
\hline
\end{tabular}

\footnotetext{
${ }^{14}$ O nível 1A, em 2015, corresponde ao 1 em 2006, enquanto o nível 1B equivale ao nível <1 no PISA 2006.
} 
É importante observar que 56,6\% dos estudantes brasileiros encontram-se abaixo do nível ${ }^{15}$ estabelecido pela OCDE como importante, na área de ciências, para que os jovens consigam exercer sua cidadania de forma plena, o nível 2. Comparando com os países da América Latina ${ }^{16}$ que tiveram seus resultados aceitos, somente Peru e República Dominicana ${ }^{17}$ apresentaram mais estudantes que o Brasil abaixo do citado nível.

Pode-se observar também que somente 17,9\% dos estudantes brasileiros estão acima do nível 2 em ciências, enquanto Uruguai e Chile apresentam 29\% e 34,1\% dos seus estudantes, respectivamente, acima do mencionado nível.

É interessante perceber que os três países, cujos estudantes apresentam menor dificuldade de conhecimento epistemológico, são exatamente os que apresentam a menor taxa de estudantes abaixo do nível 2. Na Coreia do Sul, somente $14,4 \%$ dos alunos estão abaixo do mencionado patamar, enquanto na Finlândia são 11,5\% e no Canadá, 11\%.

Por isso, pode-se dizer que um ensino que valorizasse, também, o conhecimento epistemológico ao estudante brasileiro poderia, indubitavelmente, reduzir o número de indivíduos abaixo do nível mencionado, pois asseguraria condições de se observar: a ciência como uma atividade humana, cujos interesses dos cientistas influenciam suas opções; o caráter provisório desse conhecimento científico, que precisa se assinalar como aberto, passível a futura reformulação e

\footnotetext{
${ }^{15}$ No nível 2, os estudantes conseguem recorrer a conhecimento cotidiano e a conhecimento procedimental básico para identificar um explicação científica adequada, interpretar dados e identificar a questão abordada em um projeto experimental simples. Conseguem usar conhecimento científico básico ou cotidiano para identificar uma conclusão válida em um conjunto simples de dados. Os estudantes do nível 2 demonstram ter conhecimento epistemológico básico ao conseguir identificar questões que podem ser investigadas cientificamente (BRASIL, 2016, p. 49).

${ }^{16}$ (Colômbia, Costa Rica, Chile, México, Peru, Uruguai e República Dominicana).

${ }^{17}$ Não aparece na figura 3, mas apresenta 85,7\% dos estudantes abaixo do nível 2 (BRASIL, 2016).
} 
mudança e a visão histórica, bem como problemática da ciência e também da construção do conhecimento, mostrando um dinamismo da ciência que precisa se entender como objeto vivo e sujeito a questionamentos (NASCIMENTO, 2009).

Sobre isso, Cachapuz Et al. (2011) ressaltam que o ensino que se centraliza no reducionismo conceitual acaba dificultando a aprendizagem dos próprios conceitos, contribuindo para a diminuição do interesse pela ciência, e salienta a importância de um ensino de ciências se aproximando à investigação científica que articule conceitos e procedimentos, bem como que valorize aspectos axiológicos e epistemológicos.

O nível de proficiência em ciências dos estudantes brasileiros pode ser delineado por unidades da Federação. A figura 4 mostra, por exemplo, que no estado do Espirito Santo 41\% dos estudantes ficaram abaixo do nível 2. Contudo, no Tocantins, somente $6 \%$ dos estudantes ficaram acima desse nível.

Figura 4 - Percentual de estudantes por nível de proficiência e unidade da Federação - ciências, PISA 2015. Fonte: dados da OCDE, INEP (BRASIL, 2016, p. 89).

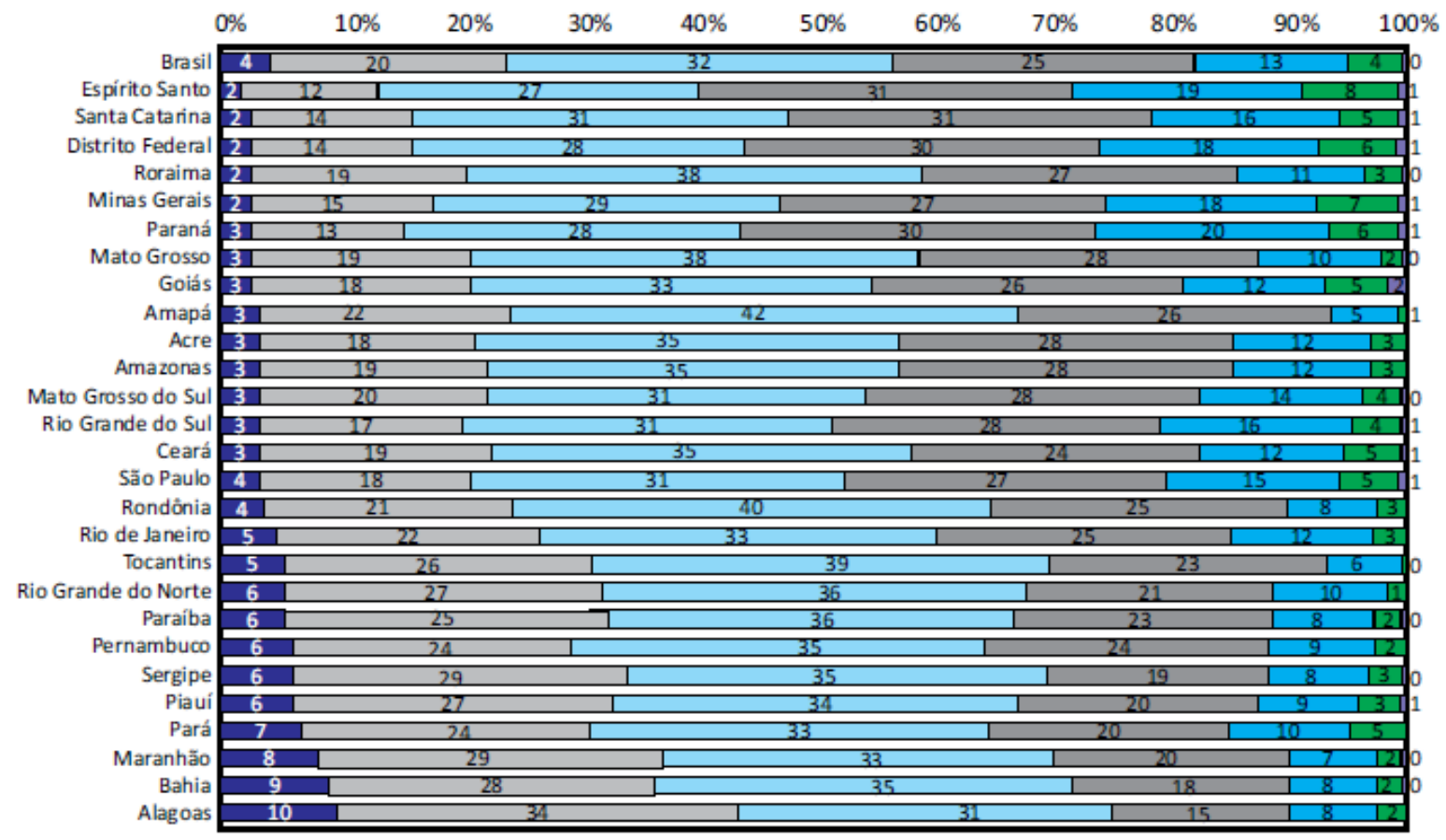

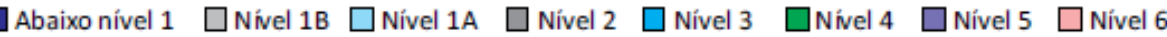


Se a figura 4 mostra que o estado do Paraná apresenta 44\% dos estudantes abaixo do nível 2, sendo superado somente pelo Espírito Santo, é bom observar que se o mesmo fosse um país, teria mais alunos, abaixo do citado nível, do que países vizinhos ao Brasil como Uruguai e Chile, por exemplo, que apresentam, respectivamente, $40,8 \%$ e $34,9 \%$ dos seus estudantes abaixo desse patamar, de acordo com a figura 3. Além disso, estaria muito distante de países como o Canadá com $11 \%$ somente dos seus alunos abaixo desse nível.

É bom lembrar que o PISA 2015 direciona sua avaliação, na área de ciências, às competências, porém o ensino de ciências apresenta como um dos seus problemas a não integração de ações "que habilite competências em seu período de formação aliado a um fomento de ações de flexibilização de currículos dos cursos formadores de professores" (DANHONI NEVES, 1998, p.75).

Por isso, um instrumento interessante para o desenvolvimento de capacidades é a solução de problemas em atividades investigativas que possam conduzir o estudante a perceber as diversas metodologias que podem ser utilizadas à solução de um problema (AZEVEDO, 2009).

Diante disso, o professor de ciências precisa estar atento aos objetivos pedagógicos, de uma atividade de investigação que busque resolver um problema, destacadas por Blosser apud Azevedo (2009, p. 24), quais sejam:

- Habilidades - de manipular, questionar, investigar, organizar, comunicar;

- Conceitos - por exemplo: hipótese, modelo teórico, categoria taxionômica;

- Habilidades cognitivas - pensamento crítico, solução de problemas, aplicação, síntese; 
- Compreensão da natureza da ciência - empreendimento científico, cientistas e como eles trabalham, a existência de uma multiplicidade de métodos científicos, inter-relações entre ciência e tecnologia e entre várias disciplinas científicas;

- Atitudes - por exemplo: curiosidade, interesse, correr risco, objetividade, precisão, perseverança, satisfação, responsabilidade, consenso, colaboração, gostar de ciência.

Tais objetivos refletem o quão importante é ensinar ciências partindo do ensino sobre ciências, pois além de se trabalhar o conteúdo conceitual, muito valorizado nos currículos tradicionais, oportunizam-se as dimensões procedimentais e atitudinais (CARVALHO, 2009), bem como os conhecimentos epistemológicos importantes ao processo de ACT dos indivíduos.

É preciso inserir o futuro professor em ações formativas que possam contemplar tais objetivos, que possam oportunizar uma reflexão sobre as inúmeras visões e representações da Ciência ${ }^{18}$ difundidas socialmente (GOLDSCHMIDT et al., 2016), ações que canalizem aspectos procedimentais como: atividades de iniciação científica, júri simulado, construção de jornais amparados em temas controversos e inclusive jogos educativos.

\section{CONSIDERAÇÕES FINAIS}

Não seria nenhum absurdo dizer que o ensino de ciências que prioriza o conhecimento de conteúdo, desprezando a importância de conhecimentos procedimentais e epistemológico é, na realidade, um processo carregado de aspectos inquisitivos, pois o conhecimento científico parece ser apresentado nessa

\footnotetext{
${ }^{18}$ Entre as principais visões de Ciências, pode-se destacar: o Indutivismo ingênuo, o Raciocínio lógico dedutivo, o Falsificacionismo, os Programas científicos, a Revoluções Científicas e o Anarquismo científico (CHALMERS, 1993; GOLDSCHMIDT et al., 2016).
} 
perspectiva para se estimular a memorização e, ao mesmo tempo, para se mitigar o pensamento e a criticidade. Desmembrar o conhecimento científico de sua natureza, no ensino de ciências, contribui, indubitavelmente, para a superficialidade do objeto, produzindo, com isso, visões inadequadas sobre tal conhecimento.

Parece claro que a não discussão sobre o caráter provisório do conhecimento científico, por exemplo, nas aulas de ciências, contribuirá para que o aluno entenda o conhecimento de conteúdo como verdadeiro e imutável sendo, por isso, um objeto pronto para se memorizar. A concepção de uma ciência pronta, acabada e estática é um convite à perpetuação de uma educação "bancária" em que todos são oprimidos. Não só o aluno, mas o próprio professor.

Assim, um indivíduo que viesse da Finlândia, por exemplo, participar das atividades educacionais aqui no Brasil, certamente diria que esse modelo de ensino de ciências vigente aparenta se preocupar mais em esconder do que em revelar, pois se concentra em dar o "peixe ${ }^{19 ",}$, ao invés de ensinar a "pescar" revelar desinteresses em promover a autonomia.

Além disso, o visitante finlandês provavelmente observaria um professor muito preocupado em ensinar, porém que pouco contribui para se aprender, um adestrador e domesticador que se concentra em transmitir e que pouco sabe sobre a construção ou reconstrução do conhecimento. Um professor preso a uma "caverna" cuja escuridão o confunde o distanciando da realidade e que só se aproximará desta, quando se perceber como indivíduo imperfeito e inacabado, ou seja, como humano.

\footnotetext{
${ }^{19}$ Conhecimento.

${ }^{20}$ Construir o conhecimento.
} 
Assim, não há duvidas de que a formação inicial do professor de ciências precisa se impregnar de conhecimentos epistemológicos e procedimentais, pois do contrário a ciência continuará sendo trabalhada na escola como se fosse um objeto de descoberta, um conhecimento pronto, acabado, imutável, inquestionável e, principalmente desinteressante.

\section{REFERÊNCIAS}

ALABARRACÍN, Liz Mayloy Muñoz; NARDI, Roberto. Aportes da Filosofia da Ciência na formação inicial de professores de Química e a mobilização do saber e do saber fazer na construção das representações científicas. In: GATTI, Sandra Regina Teodoro; NARDI, Roberto. (Org). A História e a Filosofia da Ciência no Ensino de Ciências: A pesquisa e suas contribuições para a prática pedagógica em sala de aula. São Paulo: Escrituras Ed., p. 199-230, 2016.

AZEVEDO, Maria Cristina P. Stella de. Ensino por Investigação: problematizando as atividades em sala de aula. In: CARVALHO, Anna Maria Pessoa de. (Org). Ensino de Ciências: unindo a pesquisa e a prática. São Paulo: Cengage Learning, p. 19-33, 2009.

BARDIN, L. (2011). Análise de conteúdo. São Paulo: Edições 70

BRASIL. Instituto Nacional de Estudos e pesquisas Educacionais Anísio Teixeira (INEP). Pisa 2015: análises e reflexões sobre o desempenho dos estudantes brasileiros. São Paulo: Fundação Santillana, 2016.

BRASIL. Ministério da Educação, Secretaria de Educação Fundamental. Parâmetros Curriculares Nacionais: Ciências Naturais. Brasília: Ministério da Educação, 1997. BRASIL. Ministério da Educação, Secretaria de Educação Média e Tecnológica. Parâmetros Curriculares Nacionais (PCN) (Ensino Médio). Brasília: MEC, 2000. 
BRASIL. Ministério da Educação. Secretaria da Educação Média e Tecnológica.

Parâmetros Curriculares Nacionais + $(\mathrm{PCN}+)$ - Ciências da Natureza e suas

Tecnologias. Brasília: MEC, 2002.

BRASIL. Ministério da Educação (MEC), Secretaria de Educação Básica (SEB), Ciências da natureza, matemática e suas tecnologias. Orientações Curriculares do Ensino Médio. Brasília: MEC/SEB, 2006.

CACHAPUZ, A. et al. (Org.). A necessária renovação do ensino de ciências. 3 ed. São Paulo: Cortez, 2011.

CASTRO, Ruth Schmitz de. Investigando as contribuições da Epistemologia e da História da Ciência no ensino de Ciências: de volta ao passado. In: GATTI, Sandra Regina Teodoro; NARDI, Roberto. (Org). A História e a Filosofia da Ciência no Ensino de Ciências: A pesquisa e suas contribuições para a prática pedagógica em sala de aula. São Paulo: Escrituras Ed., p. 29-52, 2016.

CARVALHO, Anna Maria Pessoa de. Critérios estruturantes para o ensino das Ciências. In: CARVALHO, Anna Maria Pessoa de. (Org). Ensino de Ciências: unindo a pesquisa e a prática. São Paulo: Cengage Learning, p. 1-17, 2009.

CARVALHO, Anna Maria Pessoa de; SASSERON, Lúcia Helena. Abordagens históricofilosóficas em sala de aula: questões e propostas. In: CARVALHO, Anna Maria Pessoa de. [et al.]. Ensino de Física. São Paulo: Cengage Learning, p. 107-139, 2010.

CHALMERS, A. F. O que é Ciência afinal? São Paulo: Brasiliense, 1993.

CHASSOT, A. Alfabetização científica: questões e desafios para a educação. 5 ed. ljuí: Ed. Unijuí, 2011.

DANHONI NEVES, M. C. A História da Ciência no Ensino de Física. Revista Ciência \& Educação. v. 5, n. 1, p. 73-81, 1998. 
FREIRE, Paulo. Ação cultural para a liberdade. 5 ed., Rio de Janeiro: Paz e Terra, 1981.

FREIRE, Paulo. Pedagogia da Autonomia: saberes necessários a prática educativa. São Paulo: Paz e Terra, 1996.

FREIRE, Paulo. Pedagogia do oprimido. 17 ed., Rio de janeiro: Paz e Terra, 1987.

GIL-PÉREZ, Daniel. CARVALHO, Anna Maria Pessoa de. Formação de professores de ciências. 9. ed. São Paulo: Cortez, 2009.

GOLDSCHMIDT, A. I.; SILVA, N. V.; MURÇA, J. S. E.; FREITAS, B. S. P. de. O que é Ciência? Concepções de licenciandos em Ciências Biológicas e Química. Contexto \& Educação. v. 31, n. 99, p. 173-200, 2016.

LAGO, S. R. A inquisição não acabou. Curitiba: Nossa Cultura, 2017.

MANHAS, C. Nada mais ideológico que "Escola Sem Partido". In: AÇÃO EDUCATIVA. (Org). A ideologia do movimento Escola Sem Partido: 20 autores desmontam o discurso. São Paulo: Ação Educativa, 2016.

MOREIRA, Marco Antônio. Uma abordagem Cognitivista ao Ensino de Física: a teoria da Aprendizagem Significativa de David Ausubel como sistema de referência para a organização do ensino de ciências. Porto Alegre: Ed da UFRGS, 1983.

NASCIMENTO, Viviane Briccia do. A Natureza do Conhecimento Científico e o Ensino de Ciências. In: CARVALHO, Anna Maria Pessoa de. (Org). Ensino de Ciências: unindo a pesquisa e a prática. São Paulo: Cengage Learning, p. 35-57, 2009.

OECD. PISA 2015 - Programa Internacional de Avaliação de Estudantes: matriz de avaliação de ciências (resumo do documento PISA 2015 Science Framework (2013)). OECD, 2015. Disponível em: 
<http://download.inep.gov.br/acoes_internacionais/pisa/marcos_referenciais/2015/ matriz_de_ciencias_PISA_2015.pdf>.Acesso em 07/11/2017.

PLATÃO. A república. Tradutor Enrico Corvisieri. São Paulo: Nova Cultural, 1999.

SAKAMOTO, L. "Escola Sem Partido": doutrinação comunista, coelho da páscoa e papai Noel. In: AÇÃO EDUCATIVA. (Org). A ideologia do movimento Escola Sem Partido: 20 autores desmontam o discurso. São Paulo: Ação Educativa, 2016.

Recebido em: Janeiro de 2018. Publicado em: Abril de 2018. 